\title{
The Effect of Teachers' Reinforcement on English Learning Engagement of EAL learners
}

\author{
"Simeng Wang ${ }^{1, a, \uparrow}$ Xuancheng $\mathrm{Wu}^{2, \mathrm{~b}, \uparrow}$ Zhaoyang Xiong ${ }^{3, \mathrm{c}, \uparrow}$
}

\author{
${ }^{1}$ Monash University \\ ${ }^{2}$ BNU-HKBU United International College \\ ${ }^{3}$ Southwest University \\ ${ }^{*}$ Corresponding author. Email: ${ }^{a}$ swan0032@student.monash.edu; ${ }^{b}$ n830016042@mail.uic.edu.hk; \\ ${ }^{c}$ swu100029@email.swu.edu.cn \\ These authors contributed equally.
}

\begin{abstract}
This research aimed to explore the effects of teachers' positive and negative reinforcement on students' English learning engagement when they learn English as additional languages (EAL). A total of 135 college students with English as additional languages voluntarily participated in this study. To explore the relationship between research variables, we divided participants into three groups by applying three treatments of positive reinforcement, negative reinforcement and inaction (control group) respectively in a stimulative classroom situation, and conducted the modelling analysis by using Utrecht Work Engagement Scale-Student (UWES-S). The results showed that there are significant differences in the investment intention, vitality, dedication and absorption among the three groups. To be specific, students with positive reinforcement had the highest level of engagement in English learning, followed by those with negative reinforcement, and students without any reinforcement had the lowest level of engagement in it. In conclusion, the present study indicated that EAL students with positive reinforcement had higher levels of engagement in English learning than those of negative reinforcement. Therefore, increasing the appropriate use of positive reinforcement for EAL students in their English learning will be implications for future studies.
\end{abstract}

Keywords: EAL learners, positive reinforcement, negative reinforcement, English learning, Chinese students, learning engagement

\section{INTRODUCTION}

With the globalization of the world, a huge number of people endeavor to master an additional language for their personal or societal success [1]. English thus becomes one of the main goals of second language learning because of its worldwide popularity and dominant status. Taking mainland China as an example, over 390 million people speak English as a second language [2]. However, learning a new language could encounter challenges from many aspects, such as different cultural backgrounds, learning styles and linguistic structures [3, 4]. Studies have found that Burrhus Frederic Skinner's reinforcement theory plays an important role when students are learning an additional language $[5,6]$. Therefore, this study is to explore the effect of using different reinforcement strategies in the classroom on EAL (English as an additional language) students' levels of engagement in English learning.

\subsection{English Learning of EAL students}

English language plays a prominent status in EAL students' daily life as well as educational undertaking [7]. As Oanh [8] declares, English is the ideal partner for any global language, especially in the multilingual backgrounds of Asia, where the combination between English and local languages has become a creative and natural identity marker for English multilingual users. On the academic side, an increasing numbers of Asian English-language academic journals are published in English which is close to the norms of native English in Anglophone countries [9]. Almost all Asian countries regard English as the first language after their native language, which has led to a commitment to produce qualified English speakers; thus, English is progressively 
introduced into Asian schools as the first "foreign language" for most children [9].

Nevertheless, learning English as an additional language inevitably faces obstacles and difficulties, such as cultural diversity, language learning strategies and learner motivations. As Raju and Joshith [4] claim, despite knowing the significance of English, students' different cultural backgrounds make them confused about adapting to a new language because it has a different structure, vocabulary and grammar from their native language. In addition, English as a foreign language has some special styles and needs specific techniques in learning processes [7]; however, there has undesirable learning atmosphere of foreign language for EAL students in many Asian countries, with inadequate educational resources and unclear educational policies $[4,10]$. More importantly, a lack of motivation and interest is a frequent issue experienced by EAL learners. Since learning an additional language is considered as an effort-demanding task, students are likely to be expected to concentrate their all attention and efforts on learning tasks, which may be viewed as boring and unimportant in such process of long-term effort [11]; such circumstance would lead to their loss of learning motivation. Furthermore, Children may lose their interests in learning English through constant repetition of words and sentences, driving their perfunctory work [4]. In this context, many studies, led by Gardner, have emphasized and demonstrated students' anxiety and resistance in learning new languages, which stemmed from the fear of negative evaluation and the risks they could take when trying unknown languages [12].

However, there is insufficient research on this kind of learning and teaching and few related literature and materials. Therefore, an in-depth exploration of effective learning theories and instructional strategies for English as an Additional language (EAL) learners becomes particularly necessary and meaningful. This research is conducive to expand the scope of such kind of study, involving the analysis of psychology, linguistics, pedagogy and other fields to further expand the research direction of this kind of topic.

\subsection{Reinforcement theory}

Reinforcement theory emerged from operant conditioning studied by Skinner, which is a learning mode of behaviourism [12]. Plenty of researchers clarify that reinforcement is a core concept for human beings to acquire skills and performance competence [13, 14]. In fact, reinforcement theory emphasizes to increase the probability of a behaviour to stimulate the occurrence of a response or a stimulus event [13, 15-17], which largely influences the facilitative effect on teaching and learning.

Reinforcement theory includes positive and negative reinforcement, which have different effects on learning in the classroom [18]. Positive reinforcement refers to repeating a particular stimulus event for rewarded responses to enhance a specific learning behaviour [19]; for example, teachers may provide students praises and rewards for getting high scores of quizzes to increase the continuity of getting high scores. Negative reinforcement refers to motivating students' particular behaviour in order to remove or avoid unfavourable effects [19], such as reducing homework if students get high scores in quizzes. The application of positive reinforcement in teaching has been more prevalent in the past, it is only recently several researchers have called for more attention to the importance of negative reinforcement and pointed out the effectiveness of reinforcement by escaping or avoiding "something perceived as aversive" [20].

Viewing from an objective standpoint, there is no doubt about the validity of Skinner's reinforcement theory in learning theory and classroom management [19]. As for students, the application of external motivation as a form of reinforcement, which can be seen as an operant conditioning to develop students' learning passions on particular tasks, can play a role in their positive learning outcomes to some extent [12]. Meanwhile, Skinner applies reinforcement by emphasizing immediate feedback, scaffolding, and ensuring students' success, which has actually been regularly practiced among most educational institutions [19]. As for educators, reinforcement can positively develop their teaching processes. Woolfolk and Margetts [21] point that three essential responsibilities of teachers are to create motivation, influence lifelong learning and achieve cognitive development for students; in this case, investigating whether students' learning outcomes and performance are influenced by reinforcement from the external environment becomes essential since it can help educators identify and adjust appropriate teaching methods.

Looking over the reinforcement theory for additional language learning, most literature is limited to specific external factors, such as Krashen's [22] advocacy of semantic input and English reading ability and Hymes's [23] ability to acquire vocabulary in situations, etc. However, there are few studies associating Skinner's reinforcement theory with internal learning motivation to improve the effect of additional language learning. Additionally, little research in the field regarding middle school students. Middle school is generally considered an essential stage of development in mental thinking and other aspects which requires the assistance of external forces to regulate their learning habits. Our experimental situation is thus set for middle school, so as to make up for the blank of this kind of research. 


\subsection{Reinforcement and English Learning Engagement}

As Gardner et al. [12] have discussed, the lack of learning motivation and anxiety and resistance to learning a new language is a very important dilemma for EAL students. Skinner's learning theory opens up a new way for this problem. Lai Xiaojing [24] and others put forward the feasibility of applying reinforcement theory to second language learning. Reinforcement can effectively improve students' motivation through external means, which is consistent with the second language learning barriers. Therefore, this experiment attempts to explore whether different reinforcement can effectively enhance students' engagement in English additional language. As Seifert \& Sutton [12] explain, for students, the application of external motivation can play a role in their positive learning outcomes to some extent. In the article "An introduction to positive reinforcement training and its benefits", Heidenreich [20] discussed the reinforcement effects of positive reinforcement, negative reinforcement and punishment, and finally found that positive reinforcement has the best effect, while negative reinforcement and punishment are not recommended. Given these considerations, the purpose of the present study is conducted to the differences of students' learning engagement in different reinforcement situations. We expect that both positive and negative reinforcement can promote students' learning engagement and the effect of positive reinforcement is greater than that of negative reinforcement.

\subsection{The significant of the research}

This research aims to improve and enrich the relevant theories and literature on English learning. As a nonnative English-speaking region in East Asia, there is a large gap in theory and achievements in the application of second language learning and teaching. Therefore, this research is conducive to enrich the teaching theory of EAL, and has a positive significance to expand the scope of this kind of research. This research involves the analysis of psychology, linguistics, pedagogy and other fields to further expand the research direction of this kind of topic.

In terms of practical significance, as mentioned above, with the prevalence of global internationalization, the number of EAL students is increasing, which is very important to solve the learning dilemma of EAL. According to the low learning enthusiasm of EAL students, our research takes Skinner's reinforcement theory as the guiding ideology, and finds out the possible internal problems in EAL learning, which can explore new implementable methods, so as to explore a new direction for English learning.

\subsection{The present study}

This research attempts to explore how positive and negative reinforcement affect the English learning engagement of EAL learners. The degree of engaging in English learning, positive and negative reinforcement are the research variables in our study. In order to explore the relationship between the variables, 135 college students were divided into three groups: positive reinforcement group, negative reinforcement group and control group. These three groups of participants were reinforced in different method through the situation test, and their English learning engagement was measured by the Utrecht Work Engagement Scale- Student (UWES-S). We hypothesis that both positive and negative reinforcement will promote students' English learning engagement, and further, the effect of positive reinforcement is greater than that of negative reinforcement.

\section{METHOD}

\subsection{Participants}

We collect data from 135 college students with an average age of 21 who regard English as additional languages. Recruitment information of this research opens to the entire society, including posting invitations to participate on popular social media platform world widely. We explain the benefits of participating in the study for EAL students' English language learning and promise to award certificates of merit to students for participating in the program. Sample is randomly selected, including 25 males and 110 females. All participants signed consent forms and were informed that all test data would be kept strictly confidential to make sure our study would not be spread during the analyzing time.

\subsection{Measures}

\subsubsection{Reinforcement}

We plan to carry out a qualitative situation test to measure the impact of different reinforcement methods on the participants' English learning engagement in different experimental groups. The reinforcement type of students will be measured by scenario simulation. The participants were asked to imagine themselves as a junior high school student in an English class. The participants were divided into three groups, which series of scenarios with different reinforcement methods will be presented. 135 participants were divided into positive reinforcement group $(n=48)$, negative reinforcement group $(n=49)$ and control group $(n=38)$. At the end of the test, there will be two questions to test the participants' willingness of degree of learning engagement and the degree of situation engagement. The 
specific procedure of the reinforcement is shown in the appendix.

\subsubsection{English Leaning Engagement}

The level of students' learning engagement will be tested by Utrecht Work Engagement Scale-Student (UWES-S). Based on Utrecht Work Engagement Scale (UWES), Schaufeli et al. [26] developed the Utrecht Work Engagement Scale-Student including 17 questions which can be divided into three dimensions: vigor (I feel energetic when I study), dedication (In the process of learning, even if the spirit is tired, I can recover quickly) and absorption (Study will make me concentrate). Based on this experiment, we changed the tense of the questionnaire to the future tense. Each item of the questionnaire appears in the form of declarative sentences, and the participants are asked to give a sevenlevel score. 0 means never, 1 means almost never / several times a year, 2 means seldom / once a month or less, 3 means sometimes / several times a month, 4 means often / once a week, 5 means very frequently / several times a week, 6 means always / every day. The final score is positively correlated with the level of learning engagement.

\subsection{Procedure}

Approval for the study were obtained from the Institutional Review Board of the university. All participants signed consent forms and were informed that all test data would be kept strictly confidential to make sure our study would not be spread during the analyzing time. The detail procedure of the reinforcement is shown in the appendix Participants did not made aware of the purpose of the study until after they had completed all measures. After submission, they were debriefed. They were informed of the results of the research. Participants were advised that their participation was completely voluntary, and their identification would be protected.

\section{RESULTS}

\subsection{Descriptive Statistics}

The results of the positive reinforcement group, negative reinforcement group and control group in each variable are given in Table 1 and shown graphically in Figure 1. Specifically, we find that the positive reinforcement group scores 4.52,4.85,4.81, and 4.81, respectively, on the intention to put in effort, vigor, dedication, and absorption. In the negative reinforcement group, intention to put in effort (3.79), vigor (3.39), dedication (3.05), and absorption (3.00) are scored. In the control group, 2.13 occurs on the vigor dimension, the lowest score is 1.81 on the dedication dimension, 1.78 is on the focus dimension, and 2.61 on the degree of intention to put in effort. The results showed that on the dimension of intention to put in effort (vigor, dedication, and absorption) the positive reinforcement group has the highest score, followed by the negative reinforcement group and the students in the control group score the lowest.

\subsection{Differences in learning engagement between positive and negative reinforcement groups}

The results of MNOVA show that the three groups have significant differences in the intention to put in effort, vigor, dedication and absorption. Bonferroni post hoc test shows that the positive reinforcement group have the highest score, followed by the negative reinforcement group and the control group, and there are significant differences among the three groups respectively. In other words, students in the positive reinforcement group show the highest level of learning engagement, followed by the negative reinforcement group, and the students in the control group show the lowest level of learning engagement.

The positive reinforcement group had high a score on situational engagement (4.29). While the negative reinforcement group and the control group score quite low, at 3.30 and 3.31 respectively. These scores indicate that the participants of positive reinforcement group strongly substituted into the situation, but it is difficult for the rest groups.

Table 1. Difference test

\begin{tabular}{|c|c|c|c|c|}
\hline & $\begin{array}{l}\text { Positive } \\
\text { reinforcem } \\
\text { ent }\end{array}$ & $\begin{array}{l}\text { Negative } \\
\text { reinforceme } \\
\text { nt }\end{array}$ & $\begin{array}{l}\text { Control } \\
\text { group }\end{array}$ & $F$ \\
\hline & $M$ & $M$ & $M$ & \\
\hline \multirow{3}{*}{$\begin{array}{l}\text { The intention to } \\
\text { put in effort } \\
\text { Vigor } \\
\text { Dedication }\end{array}$} & 4.52 & 3.79 & 2.61 & $52.11^{\star \star \star}$ \\
\hline & 4.85 & 3.39 & 2.13 & $46.04^{\star * \star}$ \\
\hline & 4.81 & 3.05 & 1.81 & $53.83^{\star \star \star}$ \\
\hline \multirow{2}{*}{$\begin{array}{l}\text { Absorption } \\
\text { Situational } \\
\text { engagement }\end{array}$} & 4.81 & 3.00 & 1.78 & $53.24^{\star * *}$ \\
\hline & 4.29 & $3.30^{\mathrm{a}}$ & $3.31^{\mathrm{a}}$ & $12.13^{\star \star *}$ \\
\hline
\end{tabular}

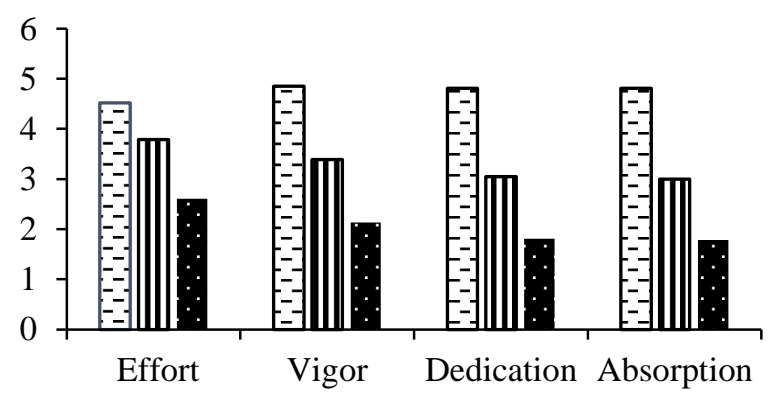

\section{$\square$ Positive reinforcement \\ o Negative reinforcement \\ Control group}

Figure 1 Differences in learning engagement and intention to put in effort between the three group. 


\section{DISCUSSION}

This study explored the effect of teachers' reinforcement on learning engagement of EAL learners. Students in the positive reinforcement group have shown the highest level of learning engagement, followed by the negative reinforcement group. Result suggested that positive reinforcement students have shown higher level of learning engagement than students who have accepted the negative reinforcement. This finding has confirmed the hypothesis.

\subsection{Positive reinforcement and learning engagement}

Positive reinforcement is a technique to elicit and to strengthen new behaviours by adding rewards and incentives instead of eliminating benefits [27]. As a concept it was that if a person was rewarded for acting in a positive way, they would come to see that behaviour as the most natural and advantageous way to act. It refers to introducing a new stimulus to the subject 's environment in order to reward the desired behaviour. Therefore, positive reinforcement brings a pleasant or desirable response and increases the possibility that the response will be repeated [28]. Behaviour which is positively reinforced has a greater probability of recurrence. This is because a positive or desirable reward is applied to the behaviour after it occurs. [29]. It associates pleasant outcome with the desired outcome. Positive reinforcement can either be a reward for good behaviour or simply a positive communication in the form of praise or encouragement. Positive reinforcement is the presentation of a stimulus after a behaviour that serves to maintain or increase the frequency of the behaviour. Another name for positive reinforcement is rewards training. Positive reinforcers tend to be valued or pleasant stimuli. To get positive reinforcers, learners often enthusiastically exceed the minimum effort necessary to gain them. Therefore, this type of training is highly recommended. In this research, teachers in the positive reinforcement group gave certain rewards to participants. Moreover, we found that this kind of reward indeed increased participants' English learning engagement. Drabman [30] reported that social reinforcers such as teacher attention, verbal praise, peer approval, and "pats on the back." have been frequently used in a variety of educational settings. This may be because teachers can easily provide them, they are naturally occurring, and are effective in changing student behaviour [31]. The delivery of verbal praise was found to increase the accuracy of reading in first grade students [32] and positive self-statements in elementary school students [33]. For the work area, positive reinforcement is also a good way to motivate employees. Yazdanifard [34] pointed out that Reinforcement theory is an instrument used by managers to increase or decrease employees' behaviours. As performance and effectiveness are more emphasized nowadays, it is important to understand and utilize these concepts in motivating staffs. Positive reinforcement is seen to be the most effective way of motivating staffs to perform better in organizations. Employees are encouraged to do better as they know when each desired behaviour is shown, they will be rewarded.

\subsection{Negative reinforcement and learning engagement}

Negative reinforcement is about removing what individuals do not like when they have performed the desired behaviour [35]. Another name for negative reinforcement is escape/avoidance training. Negative reinforcers tend to be aversive or unpleasant stimuli. To avoid negative reinforcers, learners often only work to the level necessary to avoid them [18]. In this research, teachers stimulated students' engagement in English learning by reducing homework. We found that this approach did play a certain role, but the effect was not strong enough compared with positive reinforcement. As Uddin et. al. [36] have discussed, negative reinforcement may be harmful for the students. Positive reinforcement will motivate students and build their self-confidence. Therefore, as an educational method for teachers, it is not very effective to stimulate students' learning engagement Thus, teacher should reduce the use of negative reinforcers as much as possible in the classroom as compared to positive reinforcers.

\subsection{The difference between the three groups}

Reinforcement is the way to encourage the students towards good performance or to discourage them to learn by using different types of techniques during classroom activities or outside the school compound. The main purpose of reinforcement is to activate the inner soul of a student, to make them aware about their knowing and also to inspire them not to make mistakes in future [36]. As the results of our research showed, the two groups that received reinforcement were more engaged in English learning than the control group that did not receive reinforcement. in the teaching, compared with no use of reinforcement, the use of reinforcement can get better results, and is widely adopted. Both regular and special education teachers rated the use of rewards, along with redirection, as the most effective, frequently used, and easiest classroom intervention [37]. In one study [38] elementary school teachers reported that they used reinforcement frequently to improve reading and math performance as well as increase appropriate classroom behaviour and homework completion. When teacher compliment a student for a good comment during a discussion, there is more of a chance that the comments from the student will be more often in the future. In order to motivate the students to do their homework better, the teachers reward the students with candy and so on. 


\section{LIMITATION AND IMPLICATION}

Students' engagement in learning is a critical issue among teachers, parents, and policy makers. Educators around the world spend a lot of time discussing, researching, and experimenting with strategies to increase student's engagement in learning and thus help them succeed in their academic endeavours. In this research study, the researchers investigate one approach to improving students' learning engagement. Recent research on this issue is substantive and provides many suggestions for classroom teachers. According to the research result, we find that positive reinforcement has the strongest effect on students' English learning engagement. This result is of great significance to the front-line educators. It is suggested that educators should actively use reinforcement methods, especially positive reinforcement, for students.

Although the present study provides some important findings involving the effects of teachers' positive and negative reinforcement on students' English learning engagement when they regard English as additional languages [EAL] learners, the limitations of the present study are worth noting. First, score of the negative reinforcement group is relatively low on the situational engagement, which is 3.30. The score of the sense of inclusion indicates participants could not substitute into the situation strongly. This may be because teachers do not often use negative reinforcement to increase students' academic performance [39]. Moreover, Chinese people seldom use negative reinforcement in their daily life, and rarely come into contact with it. Therefore, when the participants were tested with negative reinforcement it is quite difficult for them to have real feelings of situational engagement. Hence, it would be important in future studies to come up with some methods to enhance the level situational engagement. Second, the educational level of the participants is varied, from undergraduate to graduate, which has some influence on the study. In the future studies, it will be useful to avoid the impact of this factor.

\section{CONCLUSION}

In conclusion, the current study reveals that students with positive reinforcement have the higher level of engagement in English learning than those with negative reinforcement.

\section{Appendix}

Scenario measurement

Instruction:

Please carefully read the following materials and imagine that you are the main character in this scenario story. After reading the material, you need to answer some questions. You should choose answers by following your true beliefs. Please note that there is no right or wrong answer.

You are a first-grade student in a middle school in China, with active personality and divergent thinking, such as investigating mathematic problems and observing scientific phenomena in daily life. Meanwhile, you are good at hands-on activities, especially in drawing, painting, crafts and other artistic creations. You are in the middle to upper academic level of the whole class, but you often show a lack of motivation in English class, especially for some procedural English learning such as memorizing words and repeatedly writing sentences.

You show great enthusiasm for creative subjects that require the use of your brain or hands, such as math, physics, and chemistry. However, once you start learning English, you begin to lose concentration and wander off in class. While your classmates are earnestly reading text with the English teacher, you are often fiddling with small objects or secretly play with other things. You also procrastinate and reluctant to finish your homework after class. Therefore, even though you have worthy English foundation, your test scores are just around average. In order to improve your capabilities on memorizing words and phrases, your English teacher often assigns homework for you about writing error-prone words and sentences.

In today's English class, your teacher is explaining the use of sentence and new words of a particular unit on the podium. You start to habitually wander off again, and mindlessly doodle on your textbook. At this time, your teacher observes your little tricks, she .......

\section{【Positive reinforcement 】}

Your teacher pauses her lecture and goes to your seat, looks at the doodles on your book and said," You are very talented in drawing, and $I$ appreciate it so much, but the English textbook is not the place for your 'artistic creation'. If you can listen carefully in every English class and get more than 80 points (out of 100) on quizzes, I will recommend you take charge of the class on designing the classroom billboard. If you can continuously keep your attention in every class, I can also talk to your parents to allow you watch one more episode of your favorite documentary "Approaching Science" every day after school."

\section{【Negative reinforcement 】}

Your teacher pauses her lecture, goes to your seat and says, "If you listen carefully and get an 80 (out of 
100) or higher on the accompanying quiz, I can reduce your word writing homework by half today. If you can maintain this kind of concentration every day, I will consider giving you less word writing assignments."

\section{【Control group】}

Instead of pausing the class, your teacher ignores your little tricks and continues with the lesson.

Intention to put in effort measurement

- $\quad$ After hearing this from your teacher, how much effort do you plan to put into your future English studies?

$\begin{array}{lllllll}1 & 2 & 3 & 4 & 5 & 6 & 7\end{array}$

Substitution measurement

- $\quad$ Do you find this classroom scene vicarious? Please rate the vicariousness on a scale of 1 to 5 .

$\begin{array}{lllll}1 & 2 & 3 & 4 & 5\end{array}$

\section{REFERENCES}

[1] Nunan, D. (2003). The impact of English as a global language on educational policies and practices in the Asia-Pacific region. TESOL Quarterly, 37(4), 589613. https://doi.org/10.2307/3588214

[2] Wei, R., \& Su, J. (2012). The statistics of English in China: An analysis of the best available data from government sources. English Today, 28(3), 10-14. https://doi.org/10.1017/S026607841 2000235

[3] Raju, N.\& Joshith, V. P. (2017). Adversities and obstacles in learning English as a second language in Indian context. International Journal of Advanced Education and Research, 2(4), 48-51.

[4] Whitehurst, G. J. \& Valdez-Menchaca, M, C. (1988). What Is the Role of Reinforcement in Early Language Acquisition? Child Development 59(2), 430-440. https://doi.org/10.2307/1130322

[5] Moerk, E. L. (1986). Environmental factors in early language acquisition. Annals of child development, $3,191-236$.

[6] Khaliq, A., Douna, M, S. R., \& Ahsan, M. (2016). Role of Reinforcement or Punishment in Learning English Language: A Study at Secondary Level in Southern Punjab Pakistan. International Journal of Business and Social Science, 7(8), 137-146.

[7] Oanh, D. T. H. (2010). Global vs. Glocal English: Attitudes and Conceptions among Educators, Administrators and Teachers in Eight Asian Countries. In A. Kirkpatrick., \& R. Sussex. (2012), English as an International Language in Asia:
Implications for Language Education (1st ed.). pp. 107-135. https://doi.org/10.1007/978-94-007-45780

[8] Kirkpatrick, A., \& Sussex, Roland. (2012). English as an International Language in Asia: Implications for Language Education (1st ed.) https://doi.org/10.1007/978-94-007-4578-0

[9] Clifford, V., Rhodes, A., Paxton, G. (2013). Learning difficulties or learning English difficulties? Additional language acquisition: An update for paediatricians. Journal of Paediatrics and Child Health, 50, 175-181. https://doi.org/10.1111/jpc.12396

[10] Li, K. (2017). Motivational Regulation in Foreign Language Learning. Palgrave Macmillan. https://doi.org/10.1057/978-1-349-93118-7

[11] Horwitz, E. K., Horwitz, M. B., \& Cope, J. (1986). Foreign Language Classroom Anxiety. The Modern Language Journal 70 (2), 125-132. https://doi.org/10.2307/327317

[12] Seifert, W., \& Sutton, R. (2009). Educational Psychology (2 ${ }^{\text {nd }}$ ed.). University of Manitoba.

[13] Akinboye, J. O. (1992). Behaviour therapy and other treatment strategies. Ibadan: Paperback Publishers Limited.

[14] Oyesoji, A. A. \& Taiwo, O. (2007). Effectiveness of Vicarious Reinforcement and Contingency Contracting Techniques in Ehancing Academic Achievement of Impulsive Junior Secondary School Students in Lagos, Nigeria. Pakistan Journal of Social Sciences, 4, 705710. https://medwelljournals.com/abstract/?doi=pj ssci.2007.705.710

[15] Adenigbagbe, O.G. (1997). Psychology of human learning. Abeokuta: Stains Link.

[16] Chauhan, S. S. (1992). Advanced educational psychology. New Delhi: Vikas publishing House PVT ltd.

[17] Oladele, J. O. (2004). Educational psychology. Lagos: John Lad publishers.

[18] Heidenreich, B. (2007). An Introduction to Positive Reinforcement Training and Its Benefits. Journal of Exotic Pet Medicine, 16(1), 19-23. https://doi.org/10.1053/j.jepm.2006.11.005

[19] Omomia, O. A. \& Omomia, T. A. (2014). Relevance of Skinner's Theory of Reinforcement on Effective School Evaluaution and Management. European Journal of Psychological Studies, 4(4), 174-180. https://doi.org/10.13187/ejps.2014.4.174. 
[20] Gunter, P. L, \& Coutinho, M. J. (1997). Negative Reinforcement in Classrooms: What We're Beginning to Learn. Teacher Education and Special Education, 20(3), 249-264. https://doi.org/10.1177/088840649702000306

[21] Woolfolk, A. \& Margetts, K. (2016). Educational psychology (4th ed.). Pearson Australia.

[22] Krashen, S. D. (1982). Principles and practice in second language acquisition (1st ed.). Pergamon.

[23] Dingfang, S, \& Zhixiang, Z. (1996). Modern foreign language teaching: theory, practice and methods. Shanghai Foreign Language Education Press.

[24] Lai, X. (2015). Application of Skinner's reinforcement theory in junior high school English Vocabulary Teaching (Master's thesis, Fujian Normal University).

[25] Schaufeli, W. B., Salanova, M. \& González-romá, V. et al. (2002). The measurement of engagement and burnout and: A confirmative analytic approach, Journal of Happiness Studies, 3, 71-92. https://doi.org/10.1023/A:1015630930326

[26] Schaufeli, W. B., Salanova, M. \& GonzalezRoma, V. (2002). The measurement of engagement and burnout and: A confirmative analytic approach. Journal of Happiness Studies, 3(1), 71-92.

[27] Catania, C. A. (2001). Positive Psychology and Positive Reinforcement. American Psychologist, 56(1), 86-87. https://doi.org/10.1037/0003066X.56.1.86

[28] Wood, S. E., Wood, E. G., \& Boyd, D. (2014). The world of psychology ( $5^{\text {th }}$ Ed.). Boston: Allyn \& Bacon.

[29] Villere, M. F. \& Hartman, S. S. (1991). Reinforcement Theory: A Practical Tool. Leadership \& Organization Development Journal, (12) 2, 27-31. https://doi.org/10.1108/01437739110138039

[30] Craighead, W. E., Kazdin, Alan E, \& Mahoney, Michael J. (1976). Behavior modification: principles, issues, and applications. Houghton Mifflin.

[31] Derevensky, J. L, \& Rose, M. I. (1978). Teacher preferences for various positive reinforcements. Psychology in the Schools, 15(4), 565-570. https://doi.org/10.1002/15206807(197810)15:4<565::AIDPITS2310150421>3.0.CO;2-M

[32] Darch, C. \& Gersten, R. (1985). The effects of teacher presentation rate and praise on LD student's oral reading performance. British Journal of
Educational Psychology, 55, 295-303. https://doi.org/10.1111/j.2044-8279.1985.tb02635.x

[33] Phillips. R. H. (1984), Increasing positive selfreferent statements to improve self-esteem in lowincome elementary school children. Journal of School Psychology, 22(2), 155-163. https://doi.org/10.1016/0022-4405(84)90035-9..

[34] Wei, L. \& and Yazdanifard, R. (2014). The impact of Positive Reinforcement on Employees' Performance in Organizations. American Journal of Industrial and Business Management, 4(1), 9-12. https://doi.org/10.1016/0022-4405(84)90035-9

[35] Griggs, R. A. (2009). Psychology: A concise introduction (2nd ed.). Worth Publishers.

[36] Uddin, M. R., Hena, M. \& Shanil, A. H. (2017). Influence of Reinforcement in English Language Learning at Primary Level of Education in Bangladesh. BELTA Journal, (1)1. https://doi.org/10.36832//beltaj.2017.0101.05

[37] Martens, B. K., Peterson, R. L., Witt, J. C., \& Cirone, S. (1986). Teacher perceptions of school-based interventions. Exceptional children, 53(3), 213-223. https://doi.org/10.1177/001440298605300303.

[38] Fantuzzo, J. W., Rohrbeck, C. A., Hightower, A. D., \& Work, W. C. (1991). Teachers' use and children's preferences of rewards in elementary school. Psychology in the Schools, 28(2), 175-181. https://doi.org/10.1002/1520-

6807(199104)28:2<175::AID-

PITS2310280213>3.0.CO;2-K

[39] Berkowitz, M. J., Martens, B. K. (2001). Assessing Teachers' and Students' Preferences for SchoolBased Reinforcers: Agreement Across Methods and Different Effort Requirements. Journal of Developmental and Physical Disabilities, 13, 373387. https://doi.org/10.1023/A:1012285429759 